\title{
Cooperative Roles of Hydrophilic Loop 1 and the C-Terminus of Presenilin 1 in the Substrate-Gating Mechanism of $\gamma$-Secretase
}

\author{
Shizuka Takagi-Niidome, ${ }^{1}$ Tomoki Sasaki, ${ }^{1}$ Satoko Osawa, ${ }^{1}$ Takeshi Sato, ${ }^{2}$ Kanan Morishima, ${ }^{3}$ Tetsuo Cai, ${ }^{3}$ \\ Takeshi Iwatsubo, ${ }^{1,4}$ and $\odot$ Taisuke Tomita ${ }^{1}$ \\ ${ }^{1}$ Department of Neuropathology and Neuroscience, Graduate School of Pharmaceutical Sciences, The University of Tokyo, 7-3-1 Hongo, Bunkyo-ku, Tokyo \\ 113-0033, Japan, ${ }^{2}$ Institute for Protein Research, Osaka University, Suita, Osaka 565-0871, Japan, ${ }^{3}$ Department of Neuropathology and Neuroscience, \\ Faculty of Pharmaceutical Sciences, The University of Tokyo, 7-3-1 Hongo, Bunkyo-ku, Tokyo 113-0033, Japan, and ${ }^{4}$ Department of Neuropathology, \\ Graduate School of Medicine, The University of Tokyo, 7-3-1 Hongo, Bunkyo-ku, Tokyo 113-0033, Japan
}

$\gamma$-Secretase is a multisubunit protease complex that is responsible for generating amyloid- $\beta$ peptides, which are associated with Alzheimer disease. The catalytic subunit of $\gamma$-secretase is presenilin 1 (PS1), which contains an initial substrate-binding site that is distinct from the catalytic site. Processive cleavage is suggested in the intramembrane-cleaving mechanism of $\gamma$-secretase. However, it largely remains unknown as to how $\gamma$-secretase recognizes its substrate during proteolysis. Here, we identified that the $\alpha$-helical structural region of hydrophilic loop 1 (HL1) and the C-terminal region of human PS1 are distinct substrate-binding sites. Mutational analyses revealed that substrate binding to the HL1 region is critical for both $\varepsilon$-and $\gamma$-cleavage, whereas binding to the C-terminal region hampers $\gamma$-cleavage. Moreover, we propose that substrate binding triggers conformational changes in PS1, rendering it suitable for catalysis. Our data provide new insights into the complicated catalytic mechanism of PS1.

Key words: Alzheimer; amyloid; enzyme; intramembrane; protease; selectivity

\section{Introduction}

Hydrolysis of peptide bonds within the lipid bilayer by intramembrane-cleaving proteases is an atypical biochemical reaction that participates in numerous biological processes encompassing all branches of life. $\gamma$-Secretase is one such intramembrane-cleaving protease, and is also a possible therapeutic target for Alzheimer disease $(\mathrm{AD})$, because it is a key enzyme in the production of the amyloid- $\beta$ peptide $(A \beta)$, which is a major component of senile plaques in the brains of patients with $\mathrm{AD}$ (Holtzman et al., 2011).

Received July 30, 2014; revised Dec. 11, 2014; accepted Jan. 1, 2015.

Author contributions: S.T.-N. and T.T. designed research; S.T.-N., T. Sasaki, S.O., T. Sato, K.M., and T.C. performed research; T. Sato contributed unpublished reagents/analytic tools; S.T.-N., T. Sasaki, T. Sato, and T.T. analyzed data; S.T.-N., T. Sasaki, T.I., and T.T. wrote the paper.

This work was supported in part by Grants-in-Aid for Young Scientists (S) from the Japan Society for the Promotion of Science (JSPS; to T.T.), Scientific Research on Innovative Areas for Foundation of Synapses and Neurocircuit Pathology (T.I.) and Brain Environment (T.T.) from the Ministry of Education, Culture, Sports, Science and Technology, by Core Research for Evolutional Science and Technology of JST (T.I. and T.T.), Japan, by Takeda Science Foundation (T.T.), by the Cell Science Research Foundation (T.T.) and by a donation from Mr. Chuichi Imai (T.T.). S.T.-N. is a research fellow of JSPS. We thank Drs B. De Strooper (Katholieke Universiteit Leuven, Leuven, Belgium), R. Kopan (Washington University, St Louis, M0), T. Kitamura (The University of Tokyo, Tokyo, Japan), H. Komano (Iwate Medical University, Iwate, Japan), G Thinakaran (The University of Chicago, Chicago, IL), T. E. Golde (University of Florida, Gainesville, FL) for valuable reagents, Takeda Pharmaceutical Company (Osaka, Japan) for A $\beta$ ELISA, and our current and previous laboratory members for helpful discussions and technical assistance.

The authors declare no competing financial interests.

Correspondence should be addressed to Dr Taisuke Tomita, Department of Neuropathology and Neuroscience, Graduate School of Pharmaceutical Sciences, The University of Tokyo, 7-3-1 Hongo, Bunkyo-ku, Tokyo 113-0033, Japan.E-mail: taisuke@mol.f.u-tokyo.ac.jp.

DOI:10.1523/JNEUROSCI.3164-14.2015

Copyright $\odot 2015$ the authors $\quad 0270-6474 / 15 / 352646-11 \$ 15.00 / 0$
$\gamma$-Secretase requires four transmembrane proteins for its catalytic activity (Takasugi et al., 2003; Tomita and Iwatsubo, 2013): nicastrin (Nct), anterior pharynx defective-1 (Aph-1), presenilin enhancer-2 (Pen-2), and presenilin (PS), the latter representing the catalytic subunit. We have been applying the substituted cysteine accessibility method (SCAM) to gain insight into the structure of presenilin 1 (PS1) (Sato et al., 2006a, 2008; Takagi et al., 2010). SCAM has been repeatedly used to gain structural information on various multipass membrane proteins in a functional state, by covalently modifying the introduced cysteine (Cys) residues using sulfhydryl reagents (Karlin and Akabas, 1998). Using SCAM, we and others have revealed that PS1 harbors a hydrophilic "catalytic pore" formed by transmembrane domains (TMDs) 1, 6, 7, and 9 (Sato et al., 2006a, 2008; Tolia et al., 2006, 2008; Takagi et al., 2010). Recently, crystallographic analyses of the structures of presenilin homologues were reported (Hu et al., 2011; Li et al., 2013). Although no water molecule was detectable in these structures, the accessibility of water molecules to the catalytic site was found to be unrestricted due to the presence of a large solvent cavity, which is also consistent with previous observations obtained from SCAM. Moreover, chemical biology experiments revealed that there is an initial substrate-binding site in addition to the catalytic site in PS1 (Kornilova et al., 2005), but the relationship between the two functional sites are not well understood.

Several lines of evidence suggest that the cleavage process by $\gamma$-secretase occurs by two separate steps; endopeptidase- 
like $\varepsilon$-cleavage at the border of the membrane and the cytosol to produce the intracellular domain (ICD), followed by carboxypeptidase-like trimming, called $\gamma$-cleavage, within the hydrophobic sequence to generate short peptides (Qi-Takahara et al., 2005; Takami et al., 2009). In addition, it has been reported that the extracellular/luminal side region of the substrates is important for $\gamma$-cleavage (Ren et al., 2007; Tian et al., 2010; Kukar et al., 2011; Ousson et al., 2013), suggesting that domains located at the extracellular/luminal side in PS1 play critical roles in substrate recognition. However, the functional relationships between the two sites in PS1 and its cleavage mechanism have remained unclear. Here we found that hydrophilic loop 1 (HL1) and the most C-terminal region, which are comprised of the large portion of the extracellular/luminal side of PS1, contribute to form the "initial" substrate-binding domain at the $\varepsilon$-cleavage step, and the "second" substrate-binding site at the $\gamma$-cleavage step, respectively.

\section{Materials and Methods}

Plasmid construction, cell culture, transfection, and retroviral infection. cDNAs encoding PS1, APP carrying the Swedish mutation $\left(\mathrm{APP}_{\mathrm{NL}}\right)$, Notch $\Delta \mathrm{E}(\mathrm{N} \Delta \mathrm{E}), \mathrm{PS} 1$, and Cysless PS1 were inserted into the pMXs-puro vector (Watanabe et al., 2005; Sato et al., 2006a). PS1 mutants were generated using a long PCR-based protocol. Maintenance of embryonic fibroblasts derived from a Psen 1/Psen 2 double knock-out (DKO) mouse (Herreman et al., 2000), and HeLa or Plat-E (Kitamura et al., 2003) cells were described previously. Generation of recombinant retroviruses and stable infectant pools of DKO cells were performed as described previously (Watanabe et al., 2005).

Antibodies and immunochemical analyses. The rabbit polyclonal antibodies anti-PS1 CTF (G1L3) and anti-Pen2 (PNT3) were raised as previously described (Tomita et al., 1999; Isoo et al., 2007). The anti-Nct monoclonal antibody A5226A specifically recognizes an active form of Nct (Hayashi et al., 2012). The anti-PS1NT antibody was a kind gift from Dr G. Thinakaran (University of Chicago, Chicago, IL) (Thinakaran et al., 1998). Other antibodies were purchased from Cell Signaling Technology (anti-cleaved Notch1; V1744), Covance (anti-Aph-1aL; O2C2), IBL (anti-A $\beta ;$ 82E1), Santa Cruz Biotechnology (anti-Nct; N19), or Sigma-Aldrich (anti-Nct; N1660 and anti- $\alpha$-tubulin; DM1A). The anti$\alpha$-tubulin (AA4.3) antibody developed by Dr C. Walsh was obtained from the Developmental Studies Hybridoma Bank, created by the NICHD of the NIH and maintained at The University of Iowa, Department of Biology, Iowa City, IA 52242. Membrane fractionation, immunoblot analyses, immunoprecipitation of 3-[(3-cholamidopropyl)dimethylammonio]-2hydroxy-1-propanesulfonate (CHAPSO)-solubilized lysates, the in vitro $\gamma$-secretase assay, cycloheximide treatment, and quantitation of $\mathrm{A} \beta$ by twosite ELISA were performed as previously described (Tomita et al., 1997, Tomita et al., 1999; Takahashi et al., 2003; Takasugi et al., 2003; Watanabe et al., 2005). Cell-surface biotinylation was performed using the Pierce cell surface protein isolation kit according to the manufacturer's instructions.

Compounds, SCAM, and photoaffinity labeling. 31C and 31C-Bpa were kindly provided by Drs Naoki Umezawa and Tsunehiko Higuchi (Nagoya City University, Aichi, Japan) (Imamura et al., 2009). N-[N-(3,5-difluorophenacetyl)-L-alanyl]-(S)-phenylglycine tert-butyl ester (DAPT) and DAP-BpB were synthesized as described previously (Kan et al., 2004; Morohashi et al., 2006). Peptide 11 (pep11), peptide 15 (pep15), 17-21 peptide (LVFFA), LV- benzoylphenylalanine-FAED-biotin (17-23$\mathrm{BpB}$ ), and PS1 460-467 peptide were purchased from BEX. L-685,458, and pep11-Bt were purchased from Bachem and Ito Life Sciences, respectively. SCAM and photoaffinity labeling were performed as previously described (Morohashi et al., 2006; Sato et al., 2006a, Sato et al., 2008; Imamura et al., 2009; Takagi et al., 2010; Ohki et al., 2011). $\mathrm{N}$-biotinylaminoethyl methanethiosulfonate (MTSEA-biotin) and 2-(triethylammonium) ethyl methanethiosulfonate (MTS-TEAE) (Toronto Research Chemicals) were dissolved in DMSO at $200 \mathrm{~mm}$ and stored at -80 degrees until use. For labeling by $17-23-B p B$ (see Fig. $5 B$ ), the active $\gamma$-secretase complex was immunoprecipitated by A5226A
(Hayashi et al., 2012) from CHAPSO-solubilized HeLa membranes and used for photoaffinity labeling.

Circular dichroism analyses. Wt HL1 peptide (KSVSFYTRKDGQLIYTPFTEDTETVGQRALHSILNAAIM) and L130P/L134P HL1 peptide (KSVSFYTRKDGQLIYTPFTEDTETVGQRAPHSIPNAAIM) were purchased from BEX. 1,2-dimyristoyl-sn-glycero-3-phosphocholine (DMPC), 1,2-dimyristoyl-sn-glycero-3-phospho-(1'-rac-glycerol) (DMPG), and 1,2dihexanoyl-sn-glycero-3-phosphocholine (DHPC) were purchased from Avanti Polar Lipids. Preparation of DMPC/DMPG/DHPC bicelles was described in detail previously (Sato et al., 2006b). The bicelles were solubilized in phosphate buffer, $\mathrm{pH} 7.2$, and the final molar ratio of DMPC, DMPG, and DHPC was 10:3:13. The HL1 peptides were solubilized in the bicelle solution $(5.0 \%)$ at $1.0 \mathrm{mg} / \mathrm{ml}$. Circular dichroism (CD) measurements were performed by a J-720WI circular dichroic spectrometer (Jasco) using a 0.1-mm-thick sandwich cell. CD spectra were recorded at 25 degrees from 190 to $250 \mathrm{~nm}$.

\section{Results \\ The C-terminal region of HL1 forms a short $\alpha$-helical structure}

Previous studies suggested that HL1 of human PS1 is a long extracellular loop region formed by residues K101 to S132 (Doan et al., 1996). To elucidate the precise residues comprising HL1 in its membrane-embedded native state using SCAM, we overexpressed human PS1 mutants containing a single cysteine substitution in and around the predicted HL1 region (F105-V144) in Cysless PS1, a mutant PS1 in which five of its cysteines were substituted to serines (Cys mt PS1) (Sato et al., 2006a), in Psen $1^{-1-}$ / Psen 2 ${ }^{-1-}$ DKO cells (Herreman et al., 2000). All Cys mt PS1s except Y115C and E120C retained $\gamma$-secretase activity (Fig. 1A). SCAM analyses revealed that consecutive amino acid residues from F105C to M139C except D121C and E123C were biotinylated by MTSEA-biotin (Fig. 1B). Moreover, preincubation of MTSTEAE harboring a sterically bulkier and charged functional group decreased the labeling of almost all residues (Fig. 1C), suggesting that they are located outside of the membrane (Takagi et al., 2010). Taking into account our previous data, that MTS-TEAE decreased the labeling of K101C but not I100C, we concluded that HL1 consists of the 39 residues from K101 to M139. Several FAD mutations have been identified in HL1 region. We further tested the effect of FAD-linked P117L mutation (Wisniewski et al., 1998; Page et al., 2008) on the water accessibility of the residues on HL1. The labeling of Q127C and A129C was significantly decreased by the introduction of P117L mutation, suggesting that structural integrity of HL1 is critical to the regulation of the $\gamma$-secretase activity (Fig. 1D). Intriguingly, a periodic pattern of labeling efficiency around residues T122 to I133 was observed in the densitometric analyses of SCAM (Fig. $1 B, E$ ). Such a periodic labeling pattern in SCAM of the hydrophilic loop region was also reported for the "slide-helix" structure in the Kir channel (Enkvetchakul et al., 2007), which is located on the membrane to interact with the lipid head groups, and is involved in channel gating and protein-protein interactions. Consistent with these results, the HL1 region was predicted to be an $\alpha$-helix in secondary structure prediction programs (i.e., Jpred3 (Cole et al., 2008) and PSIPRED (McGuffin et al., 2000)), and the labeling efficiency of each residue correlated highly with its location on the surface in the helical model (Fig. $1 F$ ). Moreover, a similar region in PS orthologues from different species (e.g., Caenorhabditis elegans, Drosophila melanogaster, and Arabidopsis thaliana) was also predicted to be in an $\alpha$-helical structure, whereas the homology of their primary amino acid sequences was low (Fig. $1 G$ ). Intriguingly, MTS-TEAE did not decrease the labeling of Q127C, whereas it slightly decreased that of H131C (Fig. 1C). In contrast, 
A

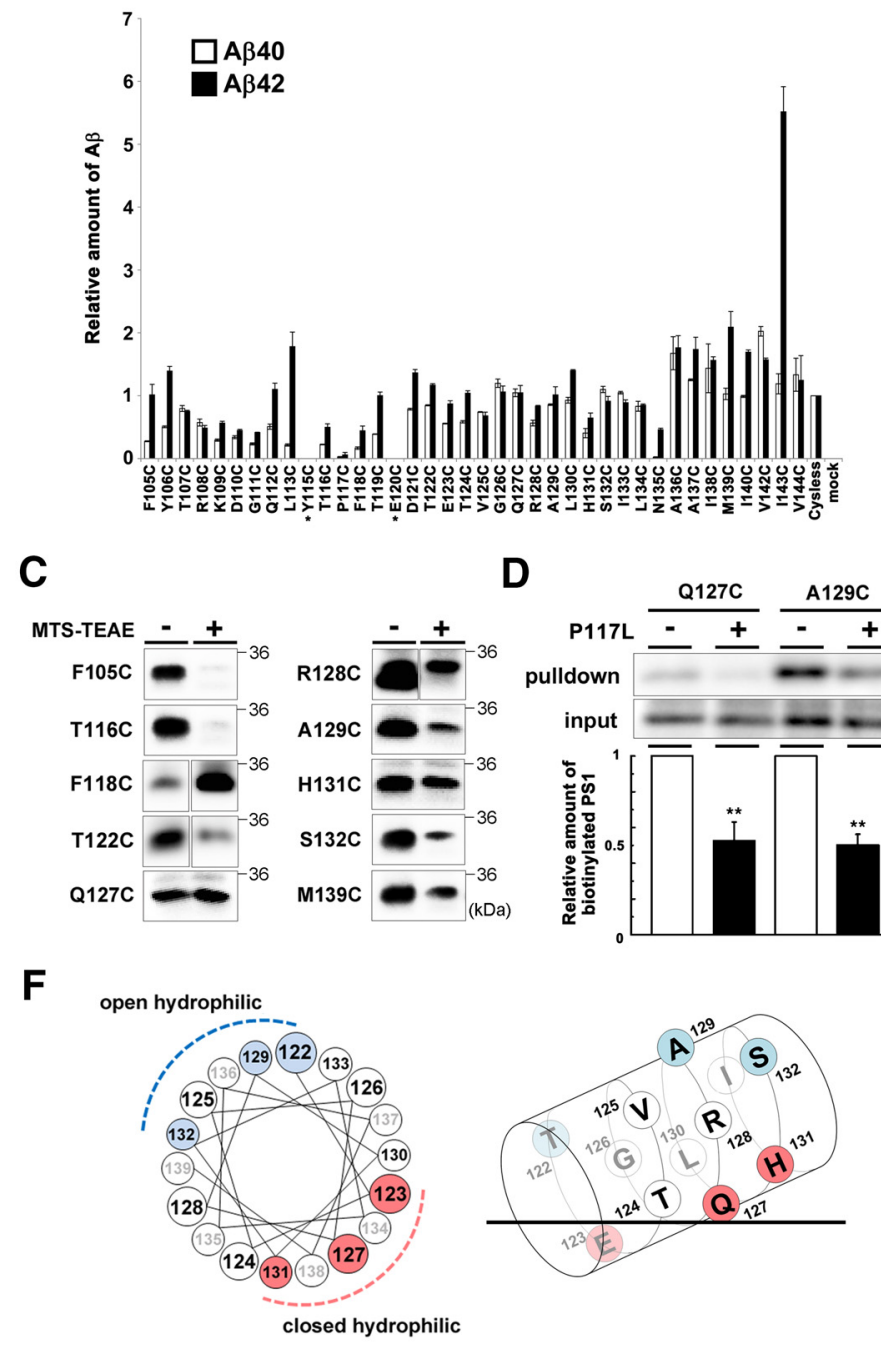

B

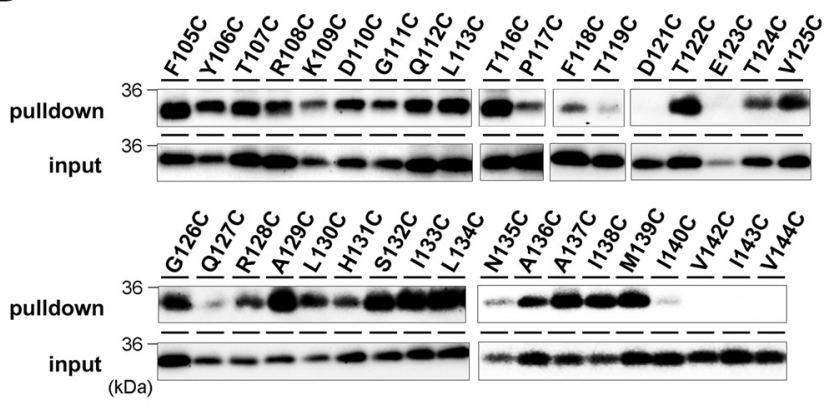

$E$

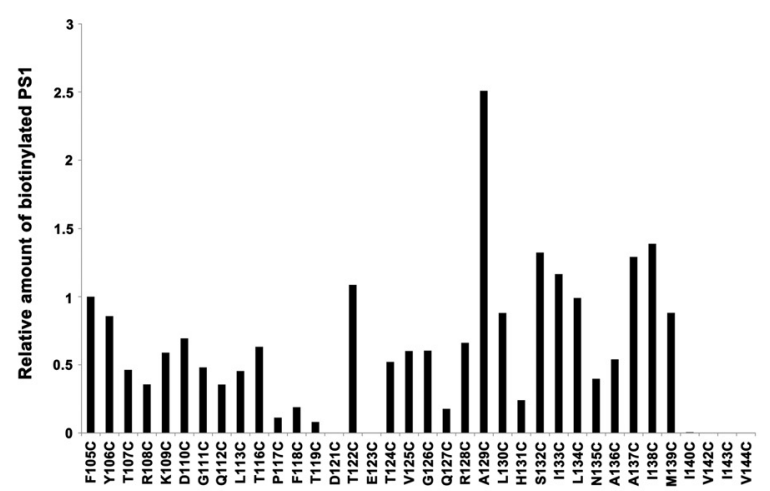

G

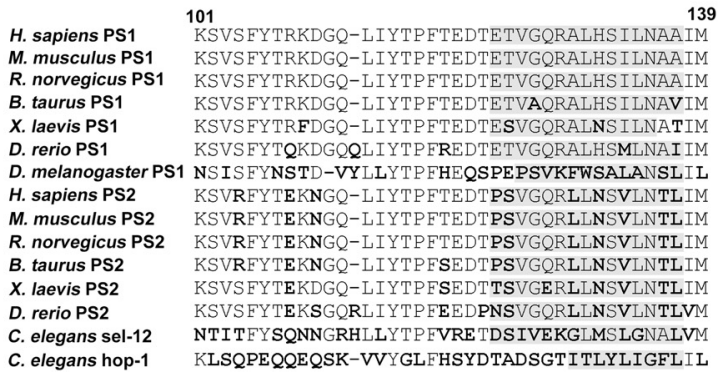

Figure 1. Structural analyses of the HL1 region of PS1. A, $\gamma$-Secretase activities in DKO cells transiently expressing Cys mt PS1. Sandwich ELISA analyses of A $\beta$ secreted from APP ${ }_{\mathrm{NL}}$-Stable DKO cells transiently transfected with Cys mt PS1 ( $n=3$, mean \pm SE). The levels of secreted A $\beta$ in conditioned media were normalized by that of cells transfected with a mutant PS1 in which 5 of its cysteines were substituted to serines (Cysless PS1). The production ratio of A $\beta 40$ and A $\beta 42$ are shown by white and black bars, respectively. B, SCAM analyses of the residues in and around the predicted HL1 region. Intact cells expressing single-Cys mt PS1 were incubated with MTSEA-biotin. Biotinylated proteins were precipitated with streptavidin beads and then subjected to immunoblot analyses. The amount of the PS1 NTF in the input fraction is shown in the bottom. C, SCAM analyses of single-Cys mt PS1 using positively charged MTS-TEAE. Biotin labeling of Cys mt PS1 was conducted after preincubation with MTS-TEAE. D, SCAM analyses of single-Cys mt PS1 (Q127C and A129C) carrying with FAD-linked P117L mutation. Relative labeling efficiency by MTSEA-biotin normalized by the input level was shown below the panels $\left(n=6\right.$, mean $\pm S E$ E; ${ }^{*} p<0.005$, Student's $t$ test.). $\boldsymbol{E}$, Quantitation of the band densities in Figure $1 B$. Labeling efficiencies were normalized to the protein expression levels (input). $\boldsymbol{F}$, (left) A helical wheel model of the residues from T122 to M139 viewed from its N-terminal side. Residues with strong and weak labeling efficiencies in $\boldsymbol{E}$ are indicated as blue and pink circles, respectively. Right, Schematic model of the structure of HL1 of PS1 in relation to the lipid bilayer, which is indicated by a black line. Residues with strong and weak labeling efficiencies are indicated as blue and pink circles, respectively. Residues with weak labeling appear periodically (i.e., E123, Q127, H131), suggesting that the tilted slide-helix structure lies on the surface of the lipid bilayer. G, Amino acid sequence alignment of HL1 of PS1 orthologues. Residues that are not conserved with human PS1 are shown in bold. The regions predicted to be in an $\alpha$-helical structure by Jpred 3 are highlighted in gray. The numbers above the sequences denote amino acid numbers in the human PS1 sequence.

the labeling of A129C and S132C was dramatically decreased by MTS-TEAE pretreatment. Considering the fact that E123C was not labeled by MTSEA-biotin, the predicted slide-helix is thought to lie on the surface of the lipid bilayer with the amino acids toward the C-terminus gradually separating from the membrane (Fig. $1 F)$.

$\alpha$-Helical structure of HL1 is critical for initial substrate binding

To obtain biophysical evidence of the helical structure of HL1 on the lipid bilayer, we performed CD spectroscopy of the synthetic HL1 peptide together with bilayered micelles (i.e., bicelles) (Sanders and Prosser, 1998; Dürr et al., 2013). The HL1 peptide exhibited two minima at 206 and $222 \mathrm{~nm}$, which are observed in a typical $\alpha$-helical conformation (Fig. $2 A$, solid line). Next, we searched for an amino acid substitution that disrupts the helical conformation using prediction programs. We found that simultaneous amino acid substitutions of both L130 and L134 to proline (Pro) (i.e., L130P/L134P) abolished the helical conformation, whereas a single Pro substitution (i.e., L130P or L134P) did not affect the structure in the prediction (Fig. 2A, left). Consistent with this, the HL1 peptide harboring the L130P/L134P mutation produced a $\mathrm{CD}$ spectrum lacking any of the typical features of canonical secondary structures (Fig. 2A, right, dotted line), suggesting that the double-Pro substitution disrupts the $\alpha$-helical conformation of HL1. Collectively, these data strongly 
A

L130P/L134P KSVSFYTRKDGQLIYTPFTEDTETVGQRAPHSIPNAAIM

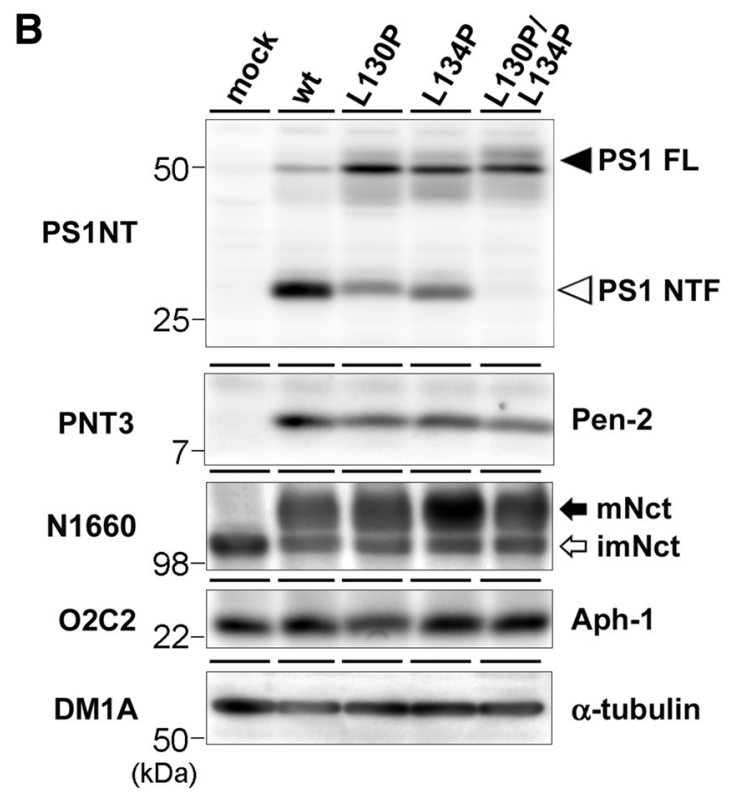

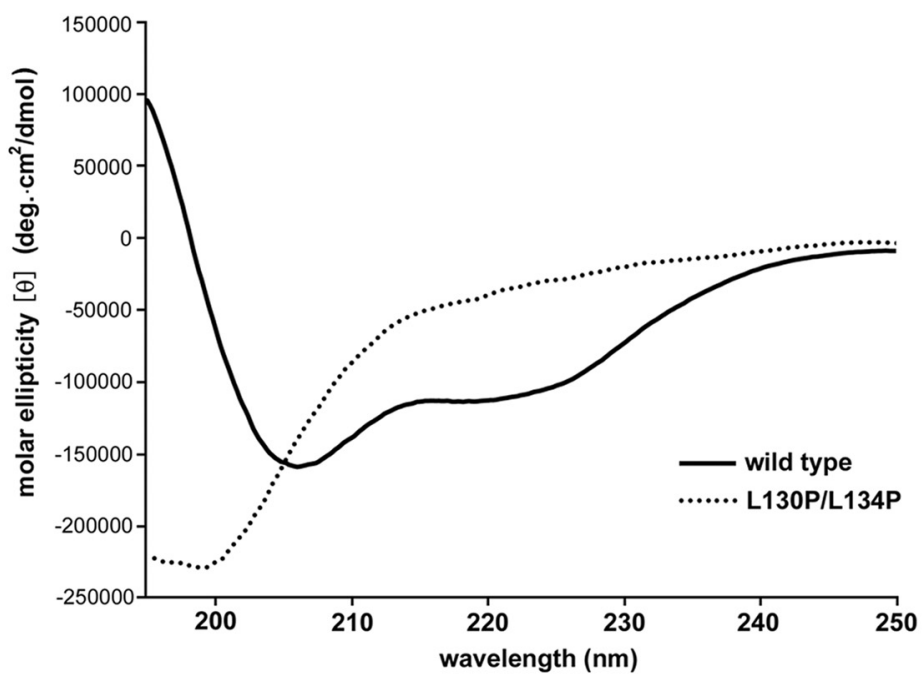

C

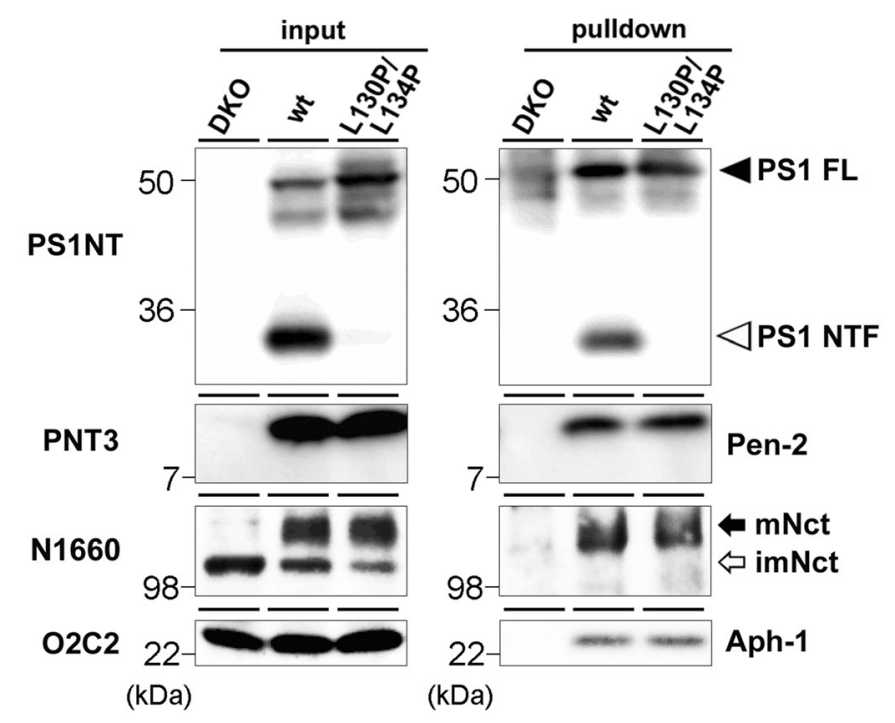

$\mathbf{E}$
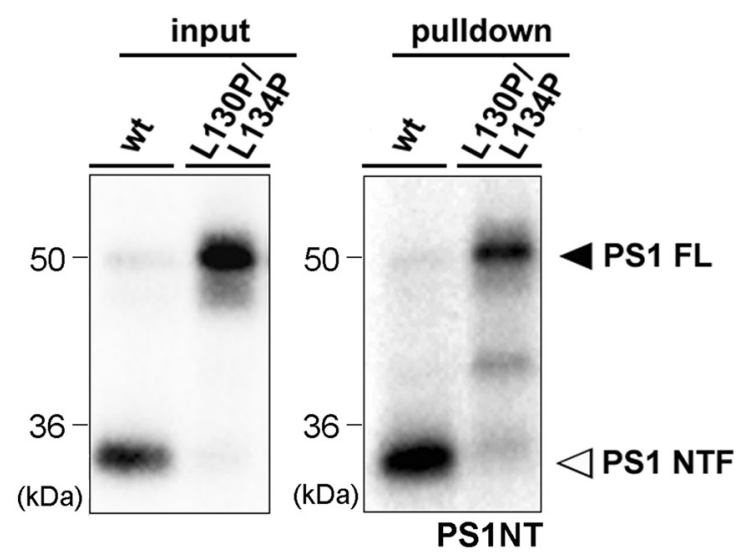

Figure 2. Biochemical characterization of Pro mt of PS1.A, Result of secondary structure prediction of HL1 region by JPred3 (left). Amino acid sequences are shown by single letters. Predicted structures are indicated below the sequence. E, Extended structure; H, helical structure. CD spectra of the wt HL1 (K101 to M139) peptide (solid line) and the L130P/L134P mutantHL1 peptide (dotted line) in DMPC/DMPG/DHPC bicelles (right). The molar ellipticity is plotted versus the wavelength. B, Immunoblot analyses of Pro mt PS1. DKO cells stably transfected with wt or Promt PS1 were analyzed by immunoblotting, with the antibody indicated at the left of each panel. FL, Full-length; $\mathrm{mNct}$, mature Nct; imNct, immature Nct. C, Coimmunoprecipitation analyses of 1\% CHAPSO-solubilized fractions prepared from DKO cells stably transfected with wt or Pro mt PS1. Solubilized fractions were precipitated with an anti-PS1 loop antibody (MAB5232) and then analyzed by immunoblotting with the antibody indicated at the left of each panel. D, DKO cells stably transfected with wt or Pro mt PS1 were incubated in media containing cycloheximide $(30 \mu \mathrm{g} / \mathrm{ml})$, and harvested after the periods indicated above the blots. Cell lysates were analyzed by immunoblotting with an anti-PS1 NTF antibody (PS1NT). FL, Full-length. E, Cell-surface biotinylation of DKO cells stably transfected with wt or Pro mt PS1. Cell lysates (input) as well as biotinylated proteins (pulldown) were analyzed by immunoblotting using PS1NT. 
A

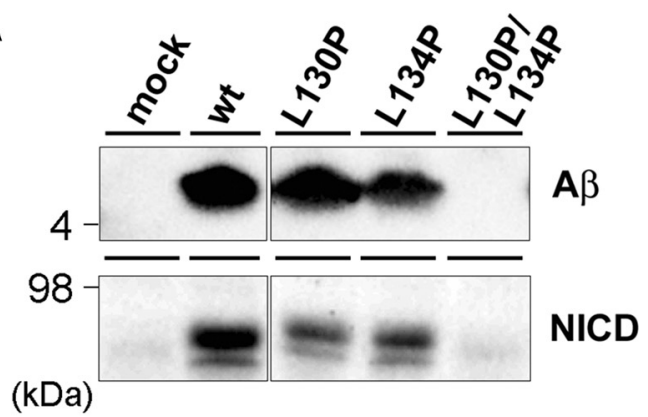

C

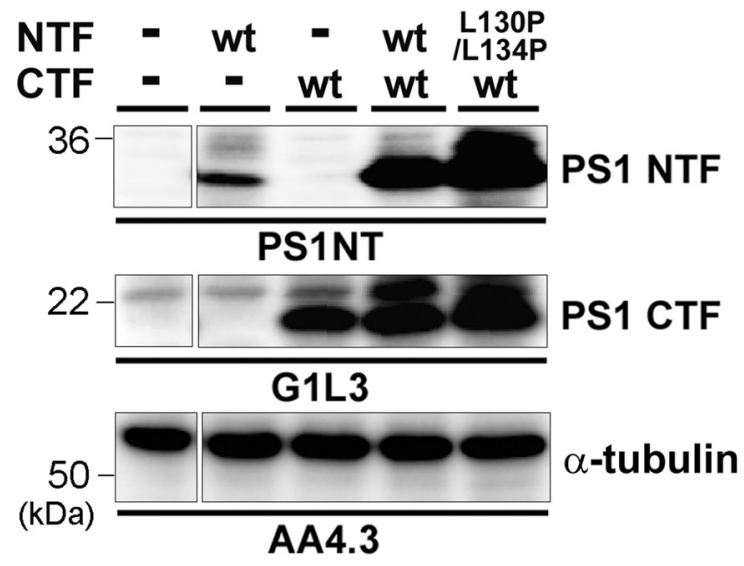

B

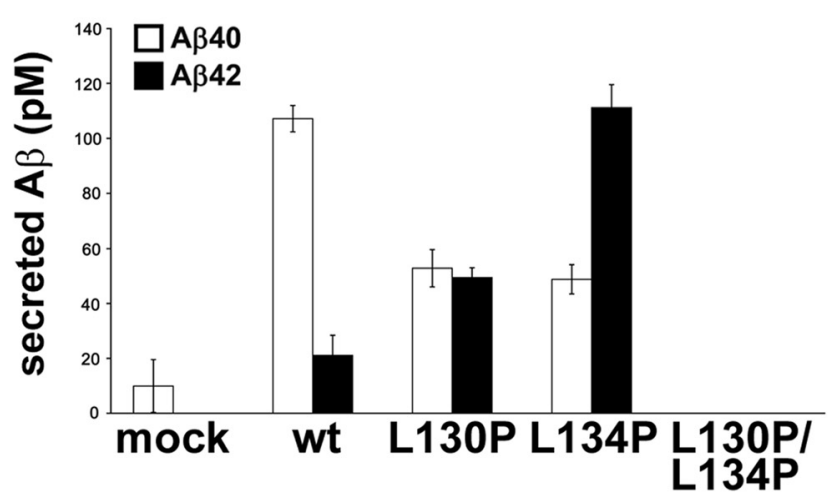

D

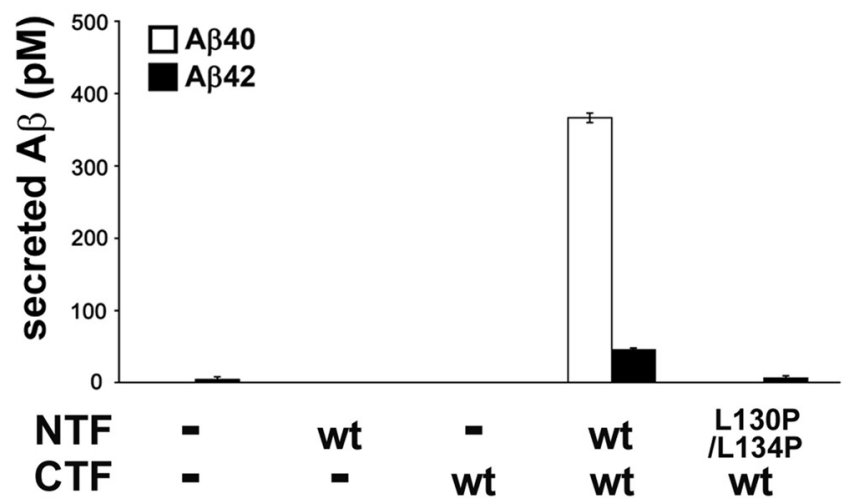

$\mathbf{E}$

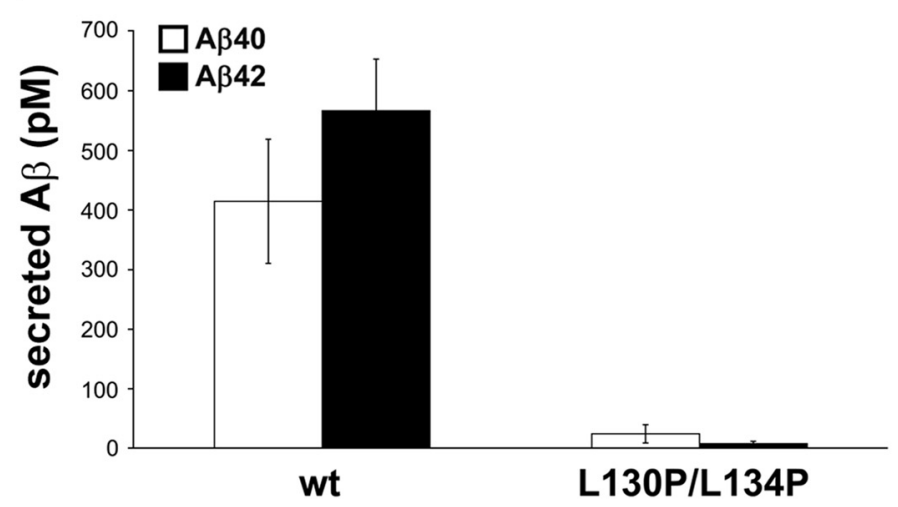

Figure 3. Effects of proline mutations of PS1 on $\gamma$-secretase activity. $A$, Immunoblot analyses of the generation of A $\beta$ from APP ${ }_{N L}$-stable DKO cells and the NICD from N $\Delta E$-stable DKO cells

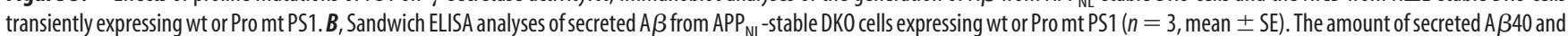
$A \beta 42$ are shown by white and black bars, respectively. C, Immunoblot analyses of DKO cells transiently coexpressing NTF and CTF of PS1. D, Sandwich ELISA analyses of secreted A $\beta$ from $\mathrm{APP}_{\mathrm{NL}}$-stable DKO cells transiently coexpressing wt or Pro $\mathrm{mt} \mathrm{NTF}$ and $\mathrm{CTF}(n=3$, mean $\pm \mathrm{SE}$ ). The amount of secreted $\mathrm{A} \beta 40$ and $\mathrm{A} \beta 42$ are shown by white and black bars, respectively. $E$, In vitro $\gamma$-secretase activities of DKO cells stably expressing wt or Pro mt PS1. Sandwich ELISA analyses of A $\beta$ generated from C100-FmH, a recombinant substrate of $\gamma$-secretase in vitro using DKO cell membranes expressing wt or Pro $\mathrm{mt}$ PS1 ( $n=3$, mean \pm SE). The amount of secreted A $\beta 40$ and A $\beta 42$ are shown by white and black bars, respectively.

support the idea that the C-terminal region of HL1 forms a short $\alpha$-helical structure on the membrane.

To examine the functional relevance of the helical structure in HL1 to the enzymatic activity of PS1, we analyzed the single- or double-Pro PS1 mutants (Pro mt PS1) stably expressed in DKO cells. All mutants maintained their expression levels, and produced mature Nct and Pen-2 at similar levels to wild-type (wt) PS1 (Fig. 2B). Notably, endoproteolysis was significantly abolished in the L130P/L134P mt PS1, although this mutant formed a stable $\gamma$-secretase complex that was detected at the cell surface, suggesting that this double mutation does not affect the biogenesis or trafficking of the $\gamma$-secretase complex (Fig. 2C-E). However, the L130P/L134P mt PS1 failed to exert $\gamma$-secretase activity for both APP and Notch in DKO cells, although the single-Pro mt produced $\mathrm{A} \beta$, as well as the Notch intracellular domain (NICD) (Fig. $3 A, B)$. Moreover, the N-terminal fragment (NTF) of L130P/L134P mt PS1 coexpressed with C-terminal fragment (CTF) of wt PS1 in DKO cells (Watanabe et al., 2010) also did not exert $\gamma$-secretase activity (Fig. $3 C, D$ ), indicating that the loss of activity of L130P/L134P mt PS1 was independent from 

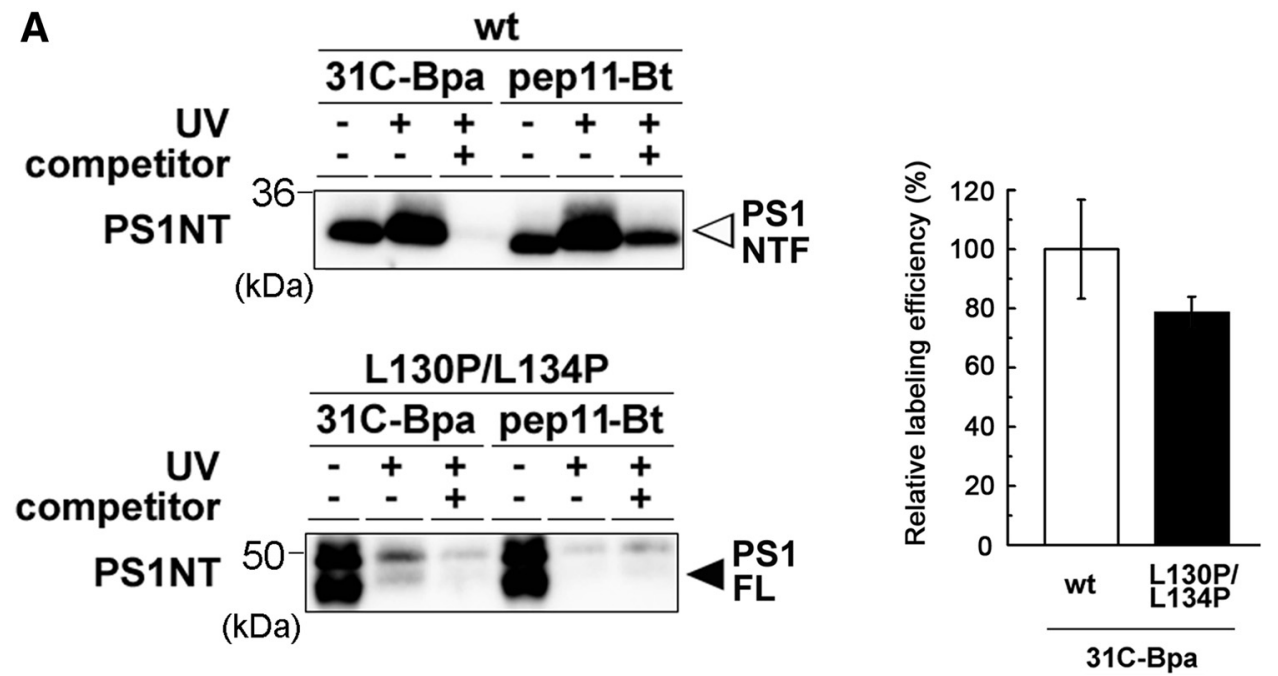

B

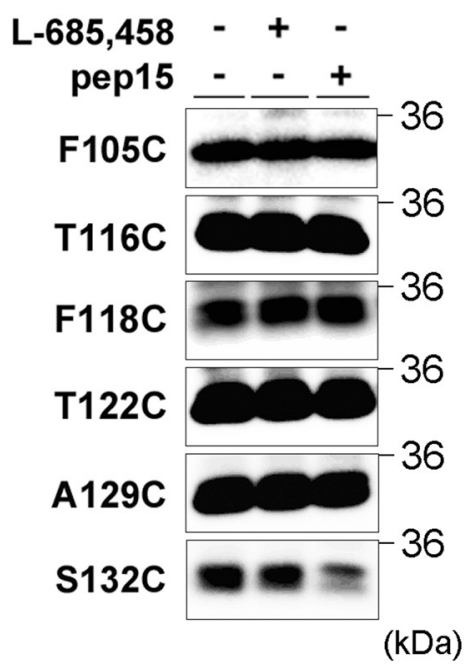

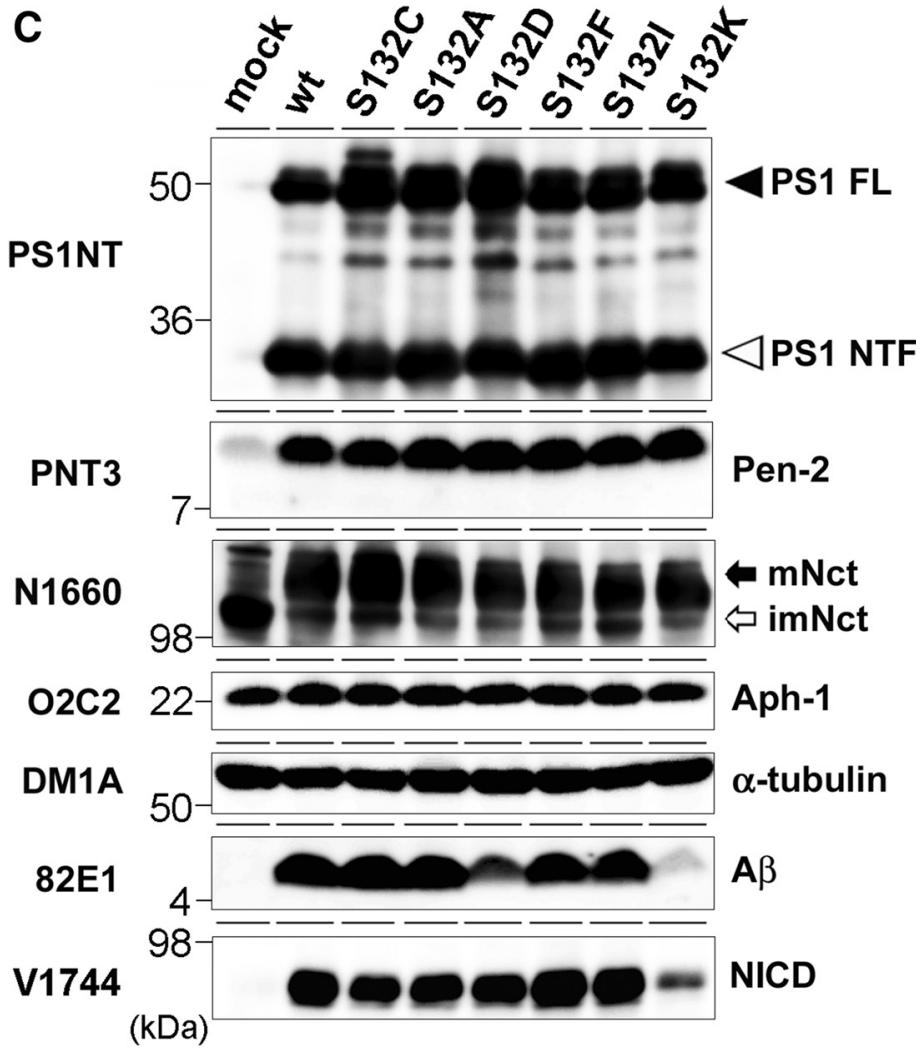

Figure 4. $\alpha$-Helical region of HL1 of PS1 is critical for the formation of the substrate-binding site. A, Photoaffinity labeling experiments of L130P/L134P PS1. CHAPS0-solubilized DK0 cell membranes expressing wt or Pro $\mathrm{mt}$ PS1 were photoactivated in the absence $(-)$ or presence $(+)$ of the parent compound as a competitor and analyzed by immunoblotting with an anti-PS1 NTF antibody (PS1NT). Relative labeling efficiency by 31C-Bpa was shown at right ( $n=3$, mean \pm SE). $B$, SCAM analyses with L-685,458 and pep15. Biotin labeling of Cys mt PS1 was conducted after preincubation with each inhibitor. C, Immunoblot analyses of S132 mt PS1. DK0 cells transiently transfected with wt or S132 mt PS1 (as indicated above the panel) were solubilized and analyzed by immunoblotting with the antibody indicated on the left. FL, Full-length; mNct, mature Nct; imNct, immature Nct.

the ineffective endoproteolysis. In addition, no proteolytic activity was observed in DKO cells expressing L130P/L134P PS1 in the in vitro $\gamma$-secretase assay (Fig. $3 E$ ), supporting the notion that the double-Pro mt PS1 intrinsically lost its enzymatic activity. Together, these data suggest that the $\alpha$-helical structure of HL1, which is sensitive to the double-Pro mutation at L130 and L134, is critical for the catalytic activity of $\gamma$-secretase.

To gain insight into the molecular mechanisms whereby the double-Pro mt lost its enzymatic activity, we performed a pho- toaffinity labeling experiment using $\gamma$-secretase inhibitor-based probes. The transition state analog-type photoprobe 31C-Bpa (Micchelli et al., 2003) and the helical peptide-type photoprobe pep11-Bt (Das et al., 2003) directly bind to the catalytic site and the initial substrate-binding site of PS1, respectively. Surprisingly, L130P/L134P mt PS1 was not labeled by pep11-Bt. Moreover, 31C-Bpa successfully biotinylated the mt PS1 (Fig. 4A), whereas labeling efficiency showed a reduced tendency. These results suggest that the $\alpha$-helical structure of HL1 might be re- 
A

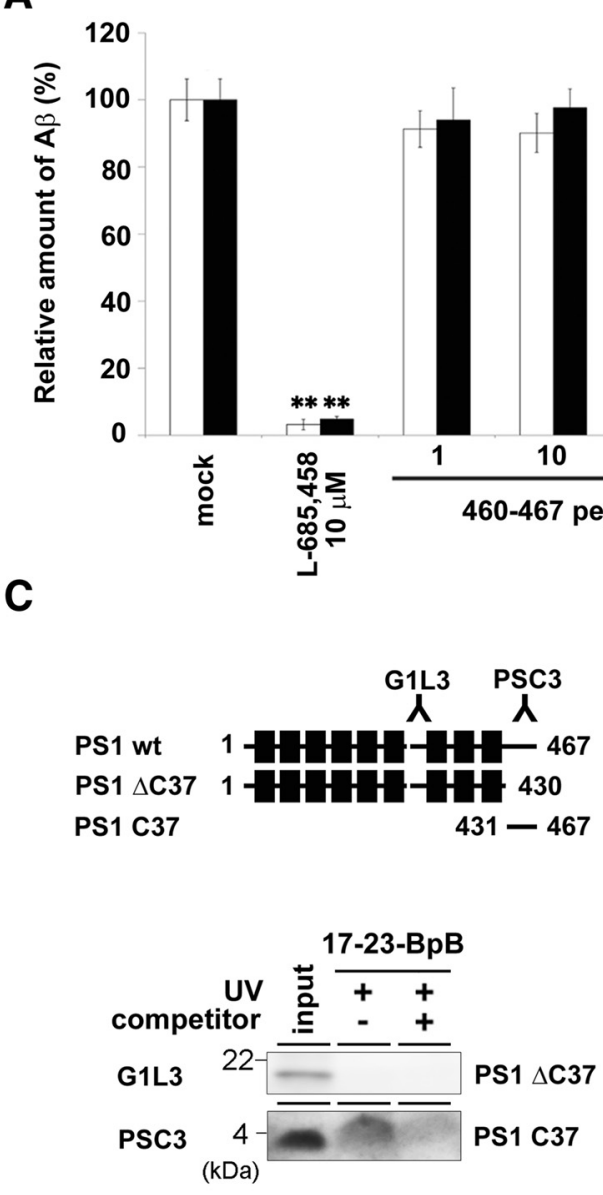

B
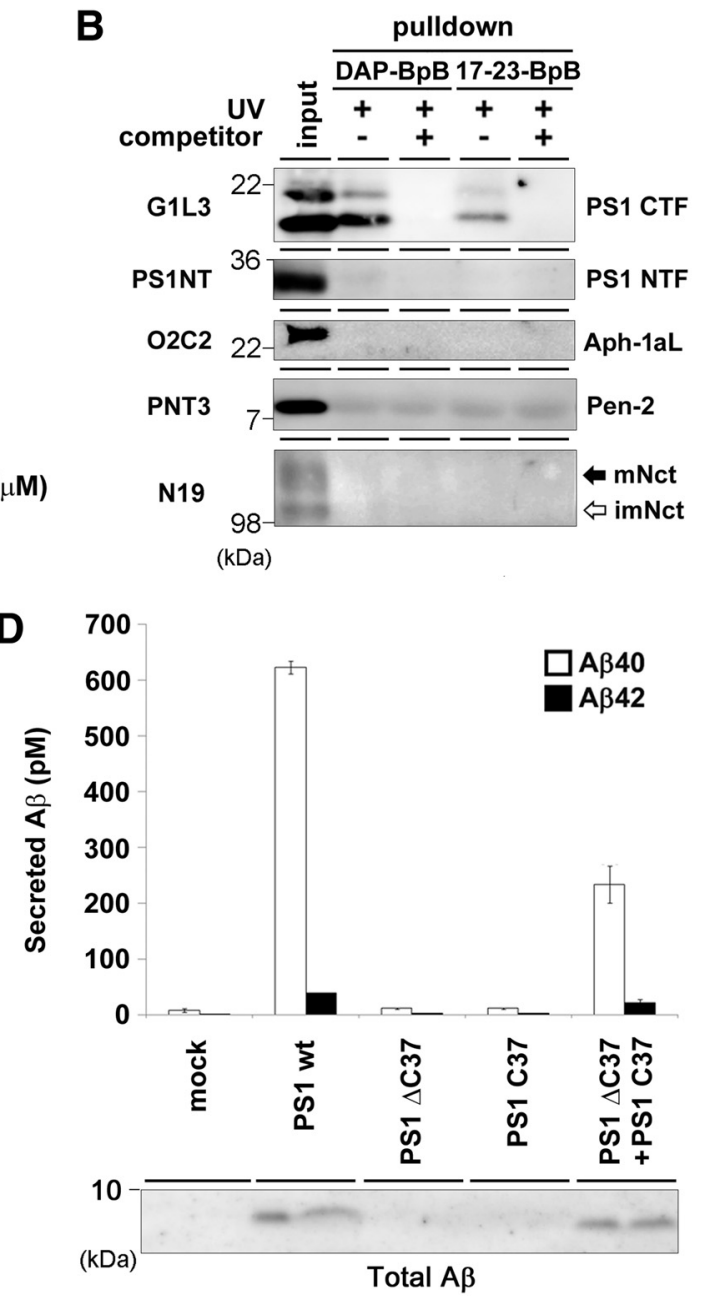

$\mathbf{E}$

D $\square \mathrm{A} \beta 40$

A $\mathrm{A42}$

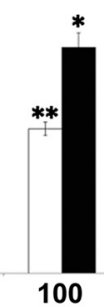
$(\mu \mathrm{M})$

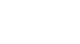

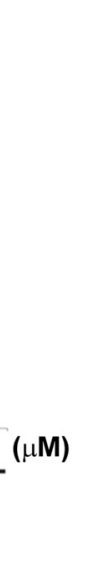

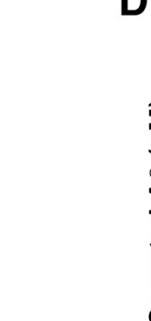

$\mathbf{E}$
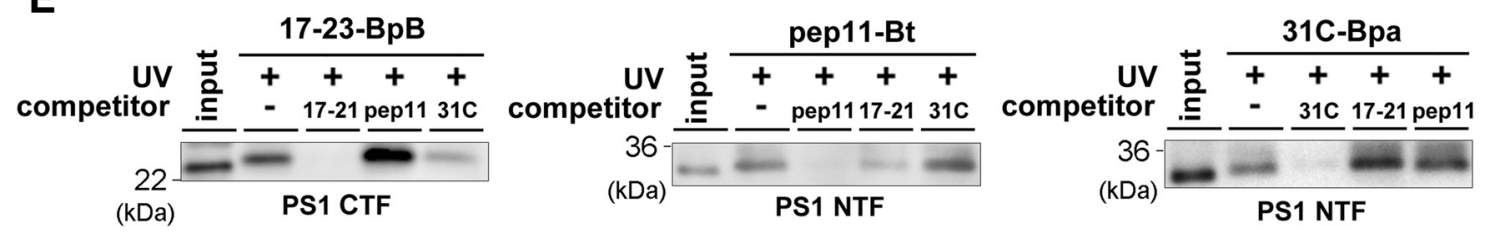

Figure 5. ASID-based photoprobe targets to the most C-terminal region of PS1. $A$, Inhibitory effect of the $460-467$ peptide (LAFHQFYI) in the in vitro $\gamma$-secretase assay using recombinant C100-FmH as a substrate $\left(n=3\right.$, mean \pm SE; ${ }^{*} p<0.05,{ }^{* *} p<0.005$, Student's t test). B, Photoaffinity labeling analyses of PS1 using the ASID-based photoprobe 17-23-BpB. CHAPSO-solubilized HeLa cell membranes were photoactivated with photoprobes (DAP-BpB or 17-23-BpB) in the absence $(-)$ or presence $(+)$ of the parent compound. mNct, Mature Nct; imNct, immature Nct. C, Labeling of the most C-terminal peptide by 17-23-BpB. Schematic presentation of split-PS constructs and the recognition sites of the antibodies are shown in the top. D, Sandwich ELISA analysis of secreted A $\beta$ from APP ${ }_{\mathrm{NL}}$-stable DK0 cells transiently expressing wt PS1, PS1 $\Delta$ C37, PS1 C37, or coexpressing PS1 $\Delta$ C37 and PS1 C37 ( $n=3$, mean \pm SE). Immunoblot analysis was shown below the graph. Note that coexpression of PS1 $\Delta$ C37 and PS1 C37 restored $\gamma$-secretase activity. E, Cross-competition analyses of photoprobes against PS1. CHAPSO-solubilized HeLa cell membranes were photoactivated in the absence or presence of the indicated compounds or peptides.

quired for the formation of the initial substrate-binding site, and the functional structure of the catalytic site of $\gamma$-secretase is formed regardless of the formation of the initial substratebinding site. To elucidate whether the short helix of HL1 is involved in substrate binding, we performed the competition assay in SCAM using the transition state analog-type $\gamma$-secretase inhibitor L-685,458 and the helical peptide-type $\gamma$-secretase inhibitor pep15 (Das et al., 2003), which is a D-peptide version of pep11 with phenylalanine instead of $o$-benzyl threonine. We found that the biotinylation of S132C was specifically decreased by preincubation with pep15, but not with L-685,458 (Fig. 4B). No other residues showed labeling competition with pep15, suggesting that $\mathrm{S} 132$ is the residue in HL1 involved in substrate binding. To further analyze the functional importance of S132, we systemat- ically mutated this residue and found that S132K mt PS1 generates dramatically less $\mathrm{A} \beta$ as well as NICD (Fig. $4 C$ ). These results indicate that S132 is a part of the initial substrate-binding site, and is critical for $\gamma$-secretase-mediated intramembrane cleavage. $\mathrm{S} 132 \mathrm{D}$ also reduced $\mathrm{A} \beta$ production, and substitutions of S132 to these amino acids did not alter the secondary structure prediction, suggesting that the charge and/or hydrophilicity might be involved in the interaction with the substrate. Notably, we found that the labeling of D450C at TMD9 of PS1, which locates at the extracellular side (Oh and Turner, 2005; Spasic et al., 2006; Sato et al., 2008), is selectively diminished by its preincubation with pep15 in the SCAM-based competition assay (Sato et al., 2008), in a similar fashion to that of S132C. In addition, we previously reported that S132 and D450 are located in proximity using a 
A
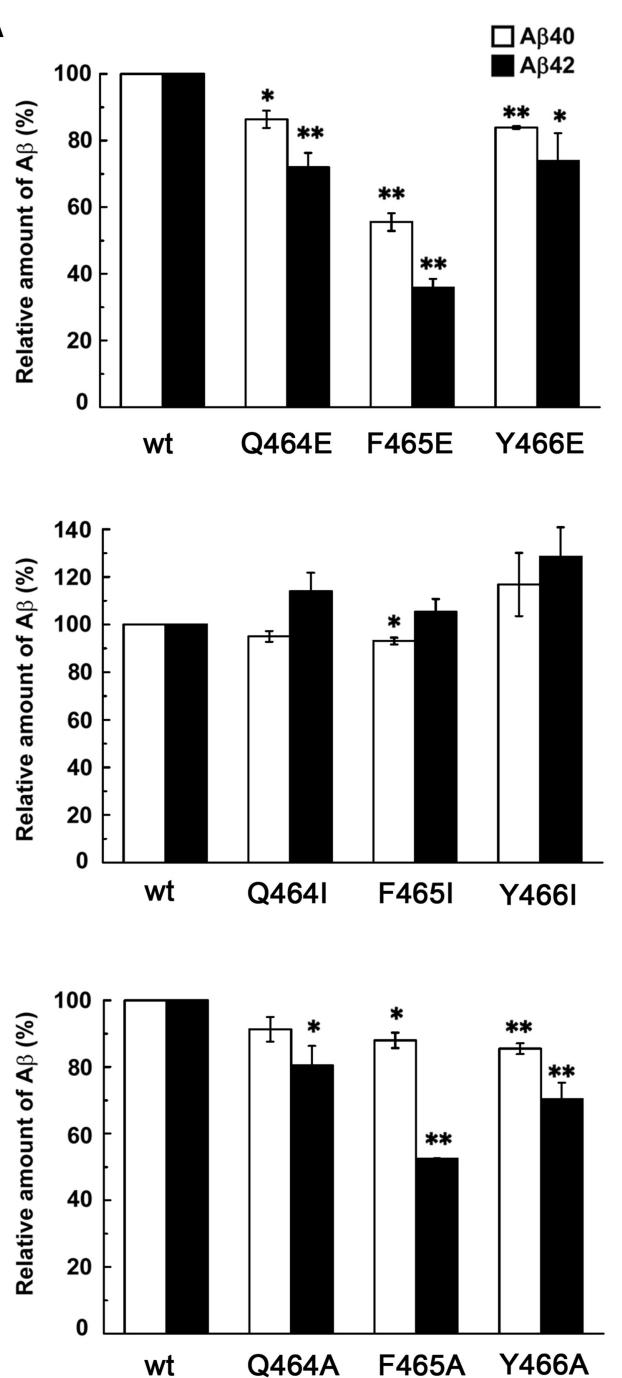

B

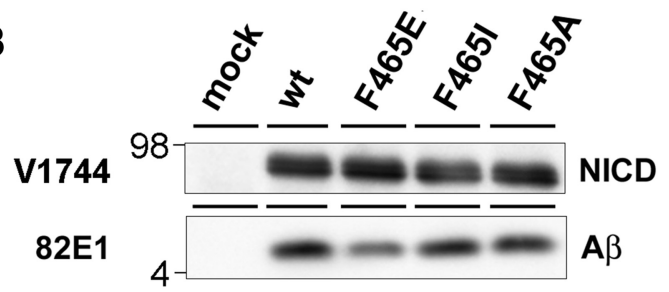

(kDa)

C

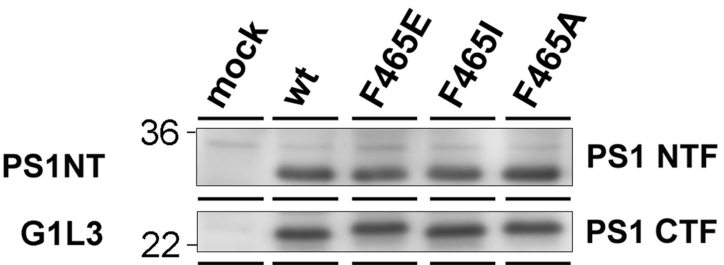

PNT3 $7, m$ Pen-2

N19

$\mathrm{O} 2 \mathrm{C} 2$

DM1A

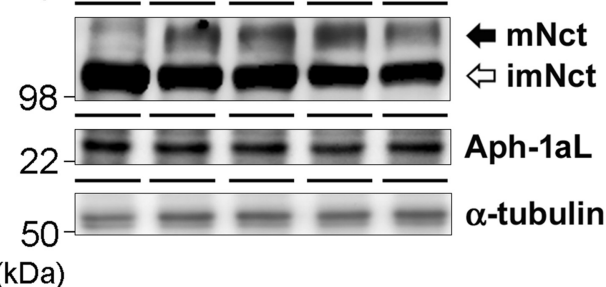

D

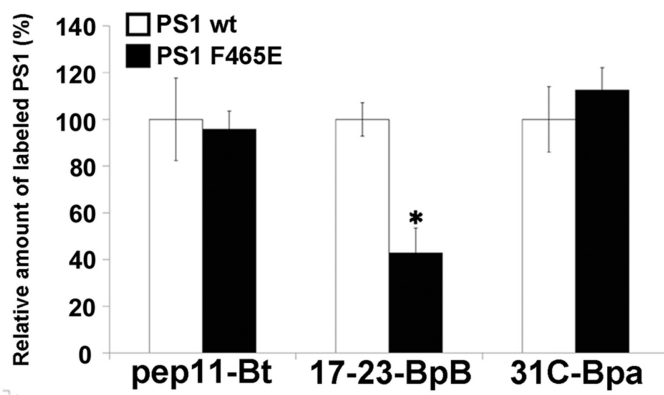

Figure 6. F465 is a critical residue for the $\gamma$-cleavage activity of PS1. A, Effects of amino acid substitutions at C-terminus of PS1 on A $\beta$ production $\left(n=3\right.$, mean $\pm S E ;{ }^{*} p<0.05$, ${ }^{* *} p<0.005$, Student's $t$ test.). $\boldsymbol{B}$, Effects of F465 mutations on $\gamma$-secretase activity. Immunoblot analyses of cell lysate (for NICD) and conditioned medium (for secreted A $\beta$ ) of DKO cells expressing F465 mt PS1 are shown. C, Immunoblot analyses of F465 mt PS1 expressed in DK0 cells. mNct, Mature Nct; imNct, immature Nct. D, Quantitation of band intensities of photolabeled PS1 CTF by 17-23-BpB. The band intensities were quantified and normalized by the protein expression levels. Relative labeling efficiencies are shown $\left(n=3\right.$, mean $\pm S E$; ${ }^{*} p<0.05$, Student's $t$ test).

cross-linking experiment (Watanabe et al., 2010). These data suggest that D450 in TMD9 contributes to the formation of the initial binding site, with S132 in HL1 positioned just above the lipid bilayer to initiate the $\varepsilon$-cleavage (see Fig. $7 A$ ).

Cooperative substrate recognition mechanism by HL1 and the C-terminus of PS1

Most of the C-terminus of PS1 has been implicated in its binding with Nct (Kaether et al., 2004) and the stabilization of the $\gamma$-secretase complex (Tomita et al., 1999). Recently, a peptide corresponding to the most C-terminal region of PS1 (aa 460467) was shown to inhibit $\mathrm{A} \beta$ production (Fig. $5 A$ ) (Esselens et al., 2012), suggesting a functional role of most of the C-terminus of PS1 in the substrate recognition mechanism of $\gamma$-secretase on the extracellular side. In this regard, we paid attention to the direct binding of PS1 with a substrate inhibitory domain (ASID) (Tian et al., 2010). ASID is a part of the extracellular side of the direct $\gamma$-secretase substrate C99 that is the cleavage product from APP. The ASID peptide has been reported to inhibit A $\beta$ generating $\gamma$-secretase activity, and to target the PS1 NTF and
CTF, and Nct. Notably, an ASID-based peptide inhibitor failed to abolish NICD production, indicating that the binding of ASID to $\gamma$-secretase might be involved in the $\gamma$-cleavage after $\varepsilon$-cleavage. We found that the photoactivatable ASID probe $\mathrm{A} \beta_{17-23} \mathrm{BPA}-$ biotin (17-23-BpB) specifically labeled the PS1 CTF in our condition (Fig. 5B) (Tian et al., 2010). To further narrow down the binding site of 17-23-BpB within the PS1 CTF, we used a complementation system using the C-terminally truncated PS1 $\Delta$ C37 and a short C-terminal fragment (PS1 C37) that is comprised of TMD9 and the most C-terminal region of PS1 (Shiraishi et al., 2006) (Fig. 5C, top). $\gamma$-Secretase activity was successfully reconstituted only by the coexpression of these recombinant proteins (Fig. 5D). A photoaffinity labeling experiment revealed that the PS1 C37 peptide, but not PS1 1 C37, is specifically labeled by $17-23-\mathrm{BpB}$. These results indicate that the luminal region of APP targets the most $\mathrm{C}$ terminal region of PS1 (Fig. $5 \mathrm{C}$, bottom). To analyze the effect of the binding between ASID and PS1 on the functional sites (i.e., the initial substrate-binding site and catalytic site) of PS1, we performed a competition experiment using the ASID peptide in the photoaffinity labeling (Fig. 5E). Preincu- 

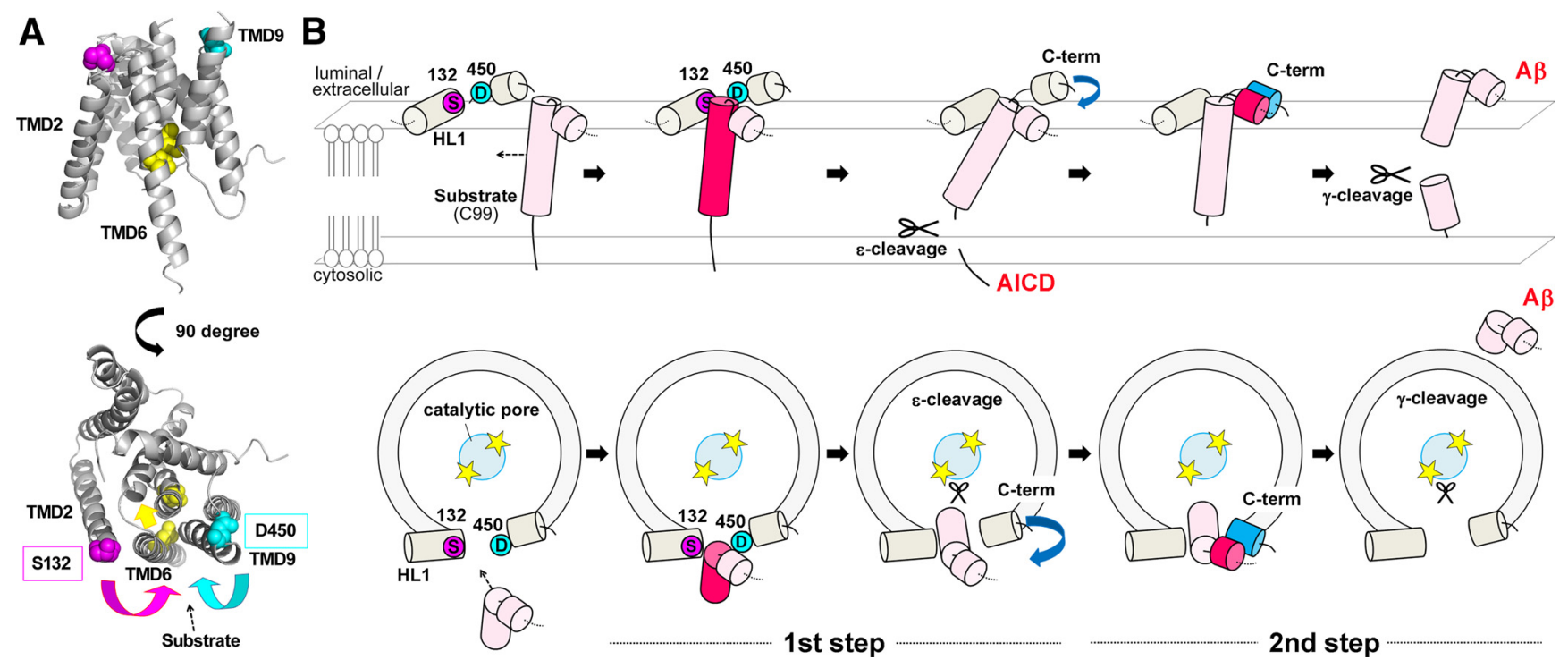

Figure 7. Schematic model of the substrate recognition process of PS1.A, Schematic depiction of the substrate-binding residues (i.e., S132, pink spheres; D450, cyan spheres) in the human PS1 model derived from the crystal structure of archaea PSH. Catalytic aspartates are represented by yellow spheres. The bottom diagram shows the view from the top. The predicted movements of TMD2, 6 , and 9 in the picking of the substrate are indicated by pink, yellow, and cyan arrows, respectively. $\boldsymbol{B}$, Schematic model of the two-step substrate-binding process of PS1. The bottom diagram shows the view from the top. The substrate is shown in pink cylinder, and binding regions of the substrate are indicated in dark pink in each step. First, the TMD and juxtamembrane region of the substrate binds to the "first" substrate-binding site formed by S132 and D450 to start $\varepsilon$-cleavage. Then, the luminal region of substrate is targeted to the "second" substrate-binding site comprised of the C-terminal region of PS1. This second interaction allows the substrate to be cleaved at the $\gamma$-site.

bation of the helical peptide-type inhibitor pep11 increased the labeling of the PS1 CTF by 17-23-BpB. In contrast, the transition state analog $31 \mathrm{C}$ significantly decreased the $17-23-\mathrm{BpB}$ labeling. In addition, the 17-21 peptide increased 31C-Bpa labeling, but inhibited the labeling of pep11-Bt. These data suggest that the binding of the APP luminal region to the PS1 C-terminus is modulated by the occupation status of these functional sites of $\gamma$-secretase by their substrates. Finally, to further characterize the functional importance of the most C-terminal region of PS1, we introduced amino acid substitutions into this region (Fig. 6A). Among the mutants, F465E significantly decreased $\mathrm{A} \beta$ production without affecting NICD production (Fig. $6 B$ ) without affecting the $\gamma$-secretase complex formation (Fig. 6C), in a similar manner to that by an ASID-based peptide inhibitor (Tian et al., 2010). In fact, the binding ability of PS1 F465E to $17-23-\mathrm{BpB}$ was significantly low, whereas the binding of $31 \mathrm{C}-\mathrm{Bpa}$ as well as pep11-Bt to PS1 F465E was almost comparable to that of wt PS1 (Fig. 6D). Thus, these results indicated that the interaction between the ASID of APP and the PS1 C-terminus, especially F465, is critical for $\gamma$-cleavage. Together, we identified two substratebinding sites in PS1; HL1/TMD9 and the C-terminus, which are selectively involved in $\varepsilon$ - and $\gamma$-cleavage, respectively.

\section{Discussion}

Although the surface loops of membrane proteins are suggested to play critical roles in their biological functions, it is challenging to reveal their structure and functional relationships using $\mathrm{x}$-ray crystallography because of their flexibility. In fact, two surface loops of the archaeal PS/SPP homolog (PSH) could not be resolved because they were disordered in the crystals ( $\mathrm{Li}$ et al., 2013). This was despite the fact that they removed the long loop 6 (HL6) and substituted 5 aa that were mostly located in the surface loops to increase the likelihood of crystallization. In addition, the loop regions of PS1 in the structures of intact $\gamma$-secretase complexes resolved by single-particle analyses were not identified because of low resolution around the membrane (Li et al., 2014; Lu et al., 2014). Because of these difficulties, biochemical approaches are still powerful tools to understand the surface regions of membrane proteins. Here, we represent the first glimpse of the functional roles of HL1 and the C-terminus of PS1 in $\varepsilon$ - and $\gamma$-cleavage using a combination of SCAM and a chemical biology approach. This confirms and strengthens the proposed ringtopology for PS1, as described previously (Annaert et al., 2001). In particular, we found that S132 and D450 are critical residues for "picking" the helical substrate just above the TMD region out of the lipid bilayer. Supporting this notion, the recombinant C99 protein was found to directly bind to GST-PS1 fusion proteins containing HL1 or the C-terminus in vitro (Annaert et al., 2001). We previously reported that the substrate entry site of PS1 is formed by TMD 2 and 6 of the NTF together with the CTF (Kornilova et al., 2005; Watanabe et al., 2010). In contrast, a structural modeling study of PS1 based on the crystal structure of PSH, TMD6, and TMD9 suggested it to be a "lateral gate" (Li et al., 2013). Intriguingly, S132 of HL1, which connects to TMD2, has been suggested to be located in proximity to TMD6 in this model. In addition, the crystal structure might represent an inactive conformation, as the distance between the two catalytic aspartates was not close enough to mediate a proteolytic reaction (Li et al., 2013). Notably, we have reported that TMDs involved in the catalytic site move closer together upon the formation of the active site (Takeo et al., 2012). Furthermore, all residues that are critical to the $\gamma$-secretase activity (i.e., L130, S132, L134, D450) are completely conserved in PS1 and PS2 (i.e., L136, S138, L140, D431, respectively). Thus, we speculate that TMD6 moves inward toward the catalytic pore in the active conformation, and the luminal pocket formed by HL1-TMD2/TMD6/TMD9 functions as the lateral gate for the helical substrate of $\gamma$-secretase (Fig. $7 A)$. And this mechanism by HL1 and C-terminal regions would be common to the PS1- and PS2-containing $\gamma$-secretase complexes. This gating model fits well with the putative substrateentry cavity in the three-dimensional structure of human 
$\gamma$-secretase determined by cryo-electron-microscopy singleparticle analysis ( $\mathrm{Lu}$ et al., 2014). Moreover, the extramembrane domains of rhomboid and site- 2 proteases, which belong to distinct-types of intramembrane proteases, have been implicated in the substrate-gating/selection mechanisms (Ha et al., 2013; Hizukuri et al., 2014). Thus, we hypothesize a common mechanism that the extracellular region of intramembrane proteases is involved in the substrate-gating machinery during catalysis. However, we are unable to exclude the possibility that other substrates might interact with PS differently, as $\gamma$-secretase cleaves several substrates other than APP and Notch. Fine structural analyses of enzyme-substrate mimetic complexes at atomic level would provide molecular functional details of the extracellular regions in intramembrane proteases.

We also provided the first mechanistic insights into the stepwise intramembrane cleavage that is one of the unique features of $\gamma$-secretase among the intramembrane-cleaving enzymes. Previous studies demonstrated that, at first, $\gamma$-secretase cleaves the substrate at the $\varepsilon$-site, which is located at the cytosolic border of the membrane. Then, successive cleavages occur at multiple $\gamma$-site(s) to release the short peptide into the extracellular side. Here we report that two distinct substrate recognition sites in PS1 are implicated in these $\varepsilon$ - and $\gamma$-cleavages. S132 and D450 of PS1, located in HL1 and TMD9, respectively, are involved in the formation of the first substrate-binding site. The second substrate recognition is achieved by the interaction between the C-terminal region of PS1 and the luminal side of the substrate (i.e., ASID of APP), both of which form a short helical structure (Beel et al., 2008). Importantly, binding of the ASID peptide to PS1 affected the binding efficiency of the helical peptide and transition-state mimic peptides in a different manner. Together with systematic mutational analyses and photoaffinity labeling experiments, we hypothesize the sequential and cooperative conformational changes of these domains, as follows: (1) a helical TMD substrate enters the initial substrate-binding site, in which S132 and D450 function as a lateral gate for the hydrophobic substrate; (2) interaction of the helical TMD and the lateral gate induce the $\varepsilon$-cleavage, as well as conformational changes in the C-terminus of PS1, to allow access of the luminal side of the substrate; and (3) successful binding of ASID and the most C-terminal region renders the structure of the catalytic pore suitable for $\gamma$-cleavage (Fig. 7B). Consistent with this model, a substrate bindinginduced conformational change in PSH was suggested, because the two catalytic aspartates are relatively separated in the crystal (Li et al., 2013). Moreover, the peptide corresponding to the C-terminal half of APP TMD, which includes the $\varepsilon$-cleavage site and binds to APP, inhibited the $\gamma$-secretase-mediated cleavage (Esselens et al., 2012). Thus, the lateral interaction with the APP TMD and the PS1 TMDs in the membrane might occur during the gating process before $\varepsilon$-cleavage, and recognize the structural integrity of these TMDs.

The two-step substrate recognition model for $\varepsilon^{-}$and $\gamma$-cleavage should provide novel insight into the mechanism of intramembrane cleavage by $\gamma$-secretase, as well as into the design of $\mathrm{AD}$ therapeutics. In particular, we recently identified that extracellular side of HL1/TM2 with TM5 is involved in the formation of the binding pocket for phenylimidazole-type $\gamma$-secretase modulators (Takeo et al., 2014). Thus, the C-terminal region of PS1, which locate in proximity to HL1/TM2, is also a novel molecular target region for the development of therapeutics using Notch-sparing $\gamma$-secretase modulators. In summary, the present study advances our understanding of the complicated mechanism of intramembrane cleavage of $\gamma$-secretase. We provide a mechanical model of two distinct substrate-binding sites that perform $\varepsilon$ - and $\gamma$-cleavage, and substrate binding to each domain triggers a conformational change in PS1 rendering it suitable for the next catalytic steps. Furthermore, this two-step recognition model provides a new therapeutic target for the design of specific inhibitors for $\mathrm{AD}$ therapies.

\section{References}

Annaert WG, Esselens C, Baert V, Boeve C, Snellings G, Cupers P, Craessaerts K, De Strooper B (2001) Interaction with telencephalin and the amyloid precursor protein predicts a ring structure for presenilins. Neuron 32: 579-589. CrossRef Medline

Beel AJ, Mobley CK, Kim HJ, Tian F, Hadziselimovic A, Jap B, Prestegard JH, Sanders CR (2008) Structural studies of the transmembrane C-terminal domain of the amyloid precursor protein (APP): does APP function as a cholesterol sensor? Biochemistry 47:9428-9446. CrossRef Medline

Cole C, Barber JD, Barton GJ (2008) The Jpred 3 secondary structure prediction server. Nucleic Acids Res 36:W197-201. CrossRef Medline

Das C, Berezovska O, Diehl TS, Genet C, Buldyrev I, Tsai JY, Hyman BT, Wolfe MS (2003) Designed helical peptides inhibit an intramembrane protease. J Am Chem Soc 125:11794-11795. CrossRef Medline

Doan A, Thinakaran G, Borchelt DR, Slunt HH, Ratovitsky T, Podlisny M, Selkoe DJ, Seeger M, Gandy SE, Price DL, Sisodia SS (1996) Protein topology of presenilin 1. Neuron 17:1023-1030. CrossRef Medline

Dürr UH, Soong R, Ramamoorthy A (2013) When detergent meets bilayer: birth and coming of age of lipid bicelles. Prog Nucl Magn Reson Spectrosc 69:1-22. CrossRef Medline

Enkvetchakul D, Jeliazkova I, Bhattacharyya J, Nichols CG (2007) Control of inward rectifier $\mathrm{K}$ channel activity by lipid tethering of cytoplasmic domains. J Gen Physiol 130:329-334. CrossRef Medline

Esselens C, Sannerud R, Gallardo R, Baert V, Kaden D, Serneels L, De Strooper B, Rousseau F, Multhaup G, Schymkowitz J, Langedijk JP, Annaert W (2012) Peptides based on the presenilin-APP binding domain inhibit APP processing and Abeta production through interfering with the APP transmembrane domain. FASEB J 26:3765-3778. CrossRef Medline

Ha Y, Akiyama Y, Xue Y (2013) Structure and mechanism of rhomboid protease. J Biol Chem 288:15430-15436. CrossRef Medline

Hayashi I, Takatori S, Urano Y, Miyake Y, Takagi J, Sakata-Yanagimoto M, Iwanari H, Osawa S, Morohashi Y, Li T, Wong PC, Chiba S, Kodama T, Hamakubo T, Tomita T, Iwatsubo T (2012) Neutralization of the gamma-secretase activity by monoclonal antibody against extracellular domain of nicastrin. Oncogene 31:787-798. CrossRef Medline

Herreman A, Serneels L, Annaert W, Collen D, Schoonjans L, De Strooper B (2000) Total inactivation of gamma-secretase activity in presenilin-deficient embryonic stem cells. Nat Cell Biol 2:461-462. CrossRef Medline

Hizukuri Y, Oda T, Tabata S, Tamura-Kawakami K, Oi R, Sato M, Takagi J, Akiyama Y, Nogi T (2014) A structure-based model of substrate discrimination by a noncanonical PDZ tandem in the intramembranecleaving protease RseP. Structure 22:326-336. CrossRef Medline

Holtzman DM, Morris JC, Goate AM (2011) Alzheimer's disease: the challenge of the second century. Sci Transl Med 3:77sr1. CrossRef Medline

Hu J, Xue Y, Lee S, Ha Y (2011) The crystal structure of GXGD membrane protease FlaK. Nature 475:528-531. CrossRef Medline

Imamura $\mathrm{Y}$, Watanabe $\mathrm{N}$, Umezawa N, Iwatsubo $\mathrm{T}$, Kato N, Tomita $\mathrm{T}, \mathrm{Hi}-$ guchi T (2009) Inhibition of gamma-secretase activity by helical betapeptide foldamers. J Am Chem Soc 131:7353-7359. CrossRef Medline

Isoo N, Sato C, Miyashita H, Shinohara M, Takasugi N, Morohashi Y, Tsuji S, Tomita T, Iwatsubo T (2007) Abeta42 overproduction associated with structural changes in the catalytic pore of gamma-secretase: common effects of Pen-2 N-terminal elongation and fenofibrate. J Biol Chem 282: 12388-12396. CrossRef Medline

Kaether C, Capell A, Edbauer D, Winkler E, Novak B, Steiner H, Haass C (2004) The presenilin C-terminus is required for ER-retention, nicastrin-binding and gamma-secretase activity. EMBO J 23:4738-4748. CrossRef Medline

Kan T, Tominari Y, Rikimaru K, Morohashi Y, Natsugari H, Tomita T, Iwatsubo T, Fukuyama T (2004) Parallel synthesis of DAPT derivatives and their gamma-secretase-inhibitory activity. Bioorg Med Chem Lett 14: 1983-1985. CrossRef Medline

Karlin A, Akabas MH (1998) Substituted-cysteine accessibility method. Methods Enzymol 293:123-145. CrossRef Medline

Kitamura T, Koshino Y, Shibata F, Oki T, Nakajima H, Nosaka T, Kumagai H (2003) Retrovirus-mediated gene transfer and expression cloning: pow- 
erful tools in functional genomics. Exp Hematol 31:1007-1014. CrossRef Medline

Kornilova AY, Bihel F, Das C, Wolfe MS (2005) The initial substratebinding site of gamma-secretase is located on presenilin near the active site. Proc Natl Acad Sci U S A 102:3230-3235. CrossRef Medline

Kukar TL, Ladd TB, Robertson P, Pintchovski SA, Moore B, Bann MA, Ren Z, Jansen-West K, Malphrus K, Eggert S, Maruyama H, Cottrell BA, Das P, Basi GS, Koo EH, Golde TE (2011) Lysine 624 of the amyloid precursor protein (APP) is a critical determinant of amyloid beta peptide length: support for a sequential model of gamma-secretase intramembrane proteolysis and regulation by the amyloid beta precursor protein (APP) juxtamembrane region. J Biol Chem 286:39804-39812. CrossRef Medline

Li X, Dang S, Yan C, Gong X, Wang J, Shi Y (2013) Structure of a presenilin family intramembrane aspartate protease. Nature 493:56-61. CrossRef Medline

Li Y, Lu SH, Tsai CJ, Bohm C, Qamar S, Dodd RB, Meadows W, Jeon A, McLeod A, Chen F, Arimon M, Berezovska O, Hyman BT, Tomita T, Iwatsubo T, Johnson CM, Farrer LA, Schmitt-Ulms G, Fraser PE, St George-Hyslop PH (2014) Structural interactions between inhibitor and substrate docking sites give insight into mechanisms of human PS1 complexes. Structure 22:125-135. CrossRef Medline

Lu P, Bai XC, Ma D, Xie T, Yan C, Sun L, Yang G, Zhao Y, Zhou R, Scheres SH, Shi Y (2014) Three-dimensional structure of human gamma-secretase. Nature 512:166-170. CrossRef Medline

McGuffin LJ, Bryson K, Jones DT (2000) The PSIPRED protein structure prediction server. Bioinformatics 16:404-405. CrossRef Medline

Micchelli CA, Esler WP, Kimberly WT, Jack C, Berezovska O, Kornilova A, Hyman BT, Perrimon N, Wolfe MS (2003) Gamma-secretase/presenilin inhibitors for Alzheimer's disease phenocopy Notch mutations in Drosophila. FASEB J 17:79-81. CrossRef Medline

Morohashi Y, Kan T, Tominari Y, Fuwa H, Okamura Y, Watanabe N, Sato C, Natsugari H, Fukuyama T, Iwatsubo T, Tomita T (2006) C-terminal fragment of presenilin is the molecular target of a dipeptidic gammasecretase-specific inhibitor DAPT (N-[N-(3,5-difluorophenacetyl)-Lalanyl]-S-phenylglycine $t$-butyl ester). J Biol Chem 281:14670-14676. CrossRef Medline

Oh YS, Turner RJ (2005) Evidence that the COOH terminus of human presenilin 1 is located in extracytoplasmic space. Am J Physiol Cell Physiol 289:C576-581. CrossRef Medline

Ohki Y, Higo T, Uemura K, Shimada N, Osawa S, Berezovska O, Yokoshima S, Fukuyama T, Tomita T, Iwatsubo T (2011) Phenylpiperidine-type gamma-secretase modulators target the transmembrane domain 1 of presenilin 1. EMBO J 30:4815-4824. CrossRef Medline

Ousson S, Saric A, Baguet A, Losberger C, Genoud S, Vilbois F, Permanne B, Hussain I, Beher D (2013) Substrate determinants in the C99 juxtamembrane domains differentially affect gamma-secretase cleavage specificity and modulator pharmacology. J Neurochem 125:610-619. CrossRef Medline

Page RM, Baumann K, Tomioka M, Pérez-Revuelta BI, Fukumori A, Jacobsen H, Flohr A, Luebbers T, Ozmen L, Steiner H, Haass C (2008) Generation of Abeta38 and Abeta42 is independently and differentially affected by familial Alzheimer disease-associated presenilin mutations and gammasecretase modulation. J Biol Chem 283:677-683. CrossRef Medline

Qi-Takahara Y, Morishima-Kawashima M, Tanimura Y, Dolios G, Hirotani N, Horikoshi Y, Kametani F, Maeda M, Saido TC, Wang R, Ihara Y (2005) Longer forms of amyloid beta protein: implications for the mechanism of intramembrane cleavage by gamma-secretase. J Neurosci 25 : 436-445. CrossRef Medline

Ren Z, Schenk D, Basi GS, Shapiro IP (2007) Amyloid beta-protein precursor juxtamembrane domain regulates specificity of gamma-secretasedependent cleavages. J Biol Chem 282:35350-35360. CrossRef Medline

Sanders CR, Prosser RS (1998) Bicelles: a model membrane system for all seasons? Structure 6:1227-1234. CrossRef Medline

Sato C, Morohashi Y, Tomita T, Iwatsubo T (2006a) Structure of the catalytic pore of gamma-secretase probed by the accessibility of substituted cysteines. J Neurosci 26:12081-12088. CrossRef Medline

Sato T, Pallavi P, Golebiewska U, McLaughlin S, Smith SO (2006b) Structure of the membrane reconstituted transmembrane-juxtamembrane peptide EGFR(622-660) and its interaction with Ca2+/calmodulin. Biochemistry 45:12704-12714. CrossRef Medline

Sato C, Takagi S, Tomita T, Iwatsubo T (2008) The C-terminal PAL motif and transmembrane domain 9 of presenilin 1 are involved in the forma- tion of the catalytic pore of the gamma-secretase. J Neurosci 28:62646271. CrossRef Medline

Shiraishi H, Marutani T, Wang HQ, Maeda Y, Kurono Y, Takashima A, Araki W, Nishimura M, Yanagisawa K, Komano H (2006) Reconstitution of gamma-secretase by truncated presenilin (PS) fragments revealed that PS C-terminal transmembrane domain is critical for formation of gammasecretase complex. Genes Cells 11:83-93. CrossRef Medline

Spasic D, Tolia A, Dillen K, Baert V, De Strooper B, Vrijens S, Annaert W (2006) Presenilin-1 maintains a nine-transmembrane topology throughout the secretory pathway. J Biol Chem 281:26569-26577. CrossRef Medline

Takagi S, Tominaga A, Sato C, Tomita T, Iwatsubo T (2010) Participation of transmembrane domain 1 of presenilin 1 in the catalytic pore structure of the gamma-secretase. J Neurosci 30:15943-15950. CrossRef Medline

Takahashi Y, Hayashi I, Tominari Y, Rikimaru K, Morohashi Y, Kan T, Natsugari H, Fukuyama T, Tomita T, Iwatsubo T (2003) Sulindac sulfide is a noncompetitive gamma-secretase inhibitor that preferentially reduces Abeta 42 generation. J Biol Chem 278:18664-18670. CrossRef Medline

Takami M, Nagashima Y, Sano Y, Ishihara S, Morishima-Kawashima M, Funamoto S, Ihara Y (2009) $\gamma$-Secretase: successive tripeptide and tetrapeptide release from the transmembrane domain of beta-carboxyl terminal fragment. J Neurosci 29:13042-13052. CrossRef Medline

Takasugi N, Tomita T, Hayashi I, Tsuruoka M, Niimura M, Takahashi Y, Thinakaran G, Iwatsubo T (2003) The role of presenilin cofactors in the gamma-secretase complex. Nature 422:438-441. CrossRef Medline

Takeo K, Watanabe N, Tomita T, Iwatsubo T (2012) Contribution of the gamma-secretase subunits to the formation of catalytic pore of presenilin 1 protein. J Biol Chem 287:25834-25843. CrossRef Medline

Takeo K, Tanimura S, Shinoda T, Osawa S, Zahariev IK, Takegami N, Ishizuka-Katsura Y, Shinya N, Takagi-Niidome S, Tominaga A, Ohsawa N, Kimura-Someya T, Shirouzu M, Yokoshima S, Yokoyama S, Fukuyama T, Tomita T, Iwatsubo T (2014) Allosteric regulation of gammasecretase activity by a phenylimidazole-type gamma-secretase modulator. Proc Natl Acad Sci U S A 111:10544-10549. CrossRef Medline

Thinakaran G, Regard JB, Bouton CM, Harris CL, Price DL, Borchelt DR, Sisodia SS (1998) Stable association of presenilin derivatives and absence of presenilin interactions with APP. Neurobiol Dis 4:438-453. CrossRef Medline

Tian Y, Bassit B, Chau D, Li YM (2010) An APP inhibitory domain containing the Flemish mutation residue modulates gamma-secretase activity for Abeta production. Nat Struct Mol Biol 17:151-158. CrossRef Medline

Tolia A, Chávez-Gutiérrez L, De Strooper B (2006) Contribution of presenilin transmembrane domains 6 and 7 to a water-containing cavity in the gammasecretase complex. J Biol Chem 281:27633-27642. CrossRef Medline

Tolia A, Horré K, De Strooper B (2008) Transmembrane domain 9 of presenilin determines the dynamic conformation of the catalytic site of gamma-secretase. J Biol Chem 283:19793-19803. CrossRef Medline

Tomita T, Iwatsubo T (2013) Structural biology of presenilins and signal peptide peptidases. J Biol Chem 288:14673-14680. CrossRef Medline

Tomita T, Maruyama K, Saido TC, Kume H, Shinozaki K, Tokuhiro S, Capell A, Walter J, Grünberg J, Haass C, Iwatsubo T, Obata K (1997) The presenilin 2 mutation (N141I) linked to familial Alzheimer disease (Volga German families) increases the secretion of amyloid beta protein ending at the 42nd (or 43rd) residue. Proc Natl Acad Sci U S A 94:2025-2030. CrossRef Medline

Tomita T, Takikawa R, Koyama A, Morohashi Y, Takasugi N, Saido TC, Maruyama K, Iwatsubo T (1999) C terminus of presenilin is required for overproduction of amyloidogenic Abeta42 through stabilization and endoproteolysis of presenilin. J Neurosci 19:10627-10634. Medline

Watanabe N, Tomita T, Sato C, Kitamura T, Morohashi Y, Iwatsubo T (2005) Pen-2 is incorporated into the gamma-secretase complex through binding to transmembrane domain 4 of presenilin 1. J Biol Chem 280: 41967-41975. CrossRef Medline

Watanabe N, Takagi S, Tominaga A, Tomita T, Iwatsubo T (2010) Functional analysis of the transmembrane domains of presenilin 1: participation of transmembrane domains 2 and 6 in the formation of initial substrate-binding site of gamma-secretase. J Biol Chem 285:1973819746. CrossRef Medline

Wisniewski T, Dowjat WK, Buxbaum JD, Khorkova O, Efthimiopoulos S, Kulczycki J, Lojkowska W, Wegiel J, Wisniewski HM, Frangione B (1998) A novel Polish presenilin-1 mutation (P117L) is associated with familial Alzheimer's disease and leads to death as early as the age of 28 years. Neuroreport 9:217-221. CrossRef Medline 